\title{
Clinical and laboratory profile of multisystem inflammatory syndrome in children: A cross-sectional study in a tertiary care hospital, Mysuru
}

\author{
Raksha Kottakki ${ }^{1}$, Sudha Rudrappa ${ }^{2}$, Pratibha Manjunath Patagar ${ }^{3}$ \\ From ' ${ }^{1}$ unior Resident, ${ }^{2}$ Professor and HOD, ${ }^{3}$ Senior Resident, Department of Pediatrics, Mysore Medical College and Research Institute, Mysore, \\ Karnataka, India
}

\begin{abstract}
Background: Multisystem inflammatory syndrome in children (MIS-C) is considered to be a rare, yet serious complication of coronavirus disease 2019, where there is immune dysregulation related to past infection with the virus. It is an inflammatory syndrome affecting multiple systems with varied manifestations including gastrointestinal, cardiovascular, respiratory, neurological, renal, hepatobiliary, and dermatological symptoms. Aim: Current study aimed to investigate the clinical and laboratory profile of MIS-C. Materials and Methods: A crosssectional study of 40 hospitalized children who were diagnosed as MIS-C and studied over a 12-month period from June 2020 to May 2021 at Cheluvamba Hospital in a tertiary care center attached to Mysore Medical College and Research Institute Mysuru, Karnataka. Results: Out of the 40 children studied, all fulfilled the diagnostic criteria of MIS-C. The most common symptom was fever (100\%), followed by gastrointestinal symptoms (90\%). The next most common system involved in our study was cardiovascular system (52.5\%). The most common laboratory findings included elevated inflammatory markers (100\%). Furthermore, there was high incidence of hematological alterations, in the form of anemia (62.5\%), thrombocytopenia (57.5\%), and neutrophilia (27.5\%). About 33.3\% cases had echocardiography abnormalities. All patients received intravenous methylprednisolone and intravenous immunoglobulin. There were six deaths (15\%) in our study and the remaining cases had good immediate outcome. Conclusion: Early recognition and prompt medical attention are necessary for a favorable outcome in MIS-C. However, there is scarcity of data regarding its long-term outcome.
\end{abstract}

Key words: Coronavirus disease 2019, Hypotensive shock, Intravenous immunoglobulin, Kawasaki-like disease, Multisystem inflammatory syndrome in children, Steroids

$\mathrm{T}$

The first cases of coronavirus disease 2019(COVID-19) were reported in January 2020 in India and were soon followed by an unexpected emergence of a novel inflammatory shock syndrome in children, in April 2020. Soon, preliminary case definitions for the inflammatory shock syndrome were named as pediatric inflammatory multisystem syndrome temporally associate with severe acute respiratory syndrome coronavirus 2 (SARS-CoV-2) (Pediatric Inflammatory Multisystem SyndromeTemporally Associated with SARS-CoV-2) by the UK Royal College of Pediatrics and Child Health and subsequently as the multisystem inflammatory syndrome in children (MIS-C), by the Centre for Disease Control and Prevention [1,2].

MIS-C can develop in previously healthy children with no known comorbidities and usually presents within 4 weeks following COVID-19 infection. However, symptoms consistent with MIS-C may appear before the resolution of COVID-19 symptoms in some

\section{Access this article online}

Received - 20 September 2021

Initial Review - 07 October 2021

Accepted - 30 October 2021

DOI: $10.32677 / \mathrm{ijch} . v 8 \mathrm{i} 11.3110$ cases. Moreover, since most of the COVID-19-infected children display mild to no symptoms, children may develop MIS-C with little to no forewarning, and in some cases, caregivers may not even be aware that the child was previously infected with COVID-19.

The pathophysiology of MIS-C is multifactorial. At present, it is believed that MIS-C is likely caused by an abnormal immune response to the coronavirus. Other possibilities include macrophage activation syndrome (MAS) and cytokine storm [2,3]. This condition shares some clinical features with viral myocarditis, Kawasaki disease, toxic shock syndrome, and MAS. It is characterized by persistent fever, gastrointestinal manifestations such as abdominal pain, vomiting and diarrhea, cardiovascular, hematological, musculoskeletal, mucocutaneous, neurological manifestations, and high inflammatory markers [1]. Among these, one of the major concerns is the involvement of cardiovascular system and the potential rapid progression into shock or cardiorespiratory failure. Despite being largely treatable and/or transient, the cardiac manifestations of MIS-C are vast and potentially life-threatening [2].

Correspondence to: Dr. Raksha Kottakki , "KASHI” Ashoknagar, Santhekatte, Udupi, Karnataka - 576 105, India. E-mail: raksha.253@gmail.com

(C) 2021 Creative Commons Attribution-NonCommercial 4.0 International License (CC BY-NC-ND 4.0). 
Within a short period of time, both, the COVID-19 and MIS-C have gained considerable interest. Current study aimed at determining the clinical and laboratory profile of MIS-C and its immediate outcome in a tertiary care hospital in Mysuru.

\section{MATERIALS AND METHODS}

We conducted a cross-sectional retrospective study of patients with MIS-C who were admitted to Cheluvamba Hospital from June 1, 2020, to May 31, 2021 (12 months). Children aged 0-18 years who fulfilled the following criteria were included in the study: (1) Children and adolescents $0-18$ years of age with fever $\geq 3$ days and (2) two of the following: (i) Rash or bilateral non purulent conjunctivitis or mucocutaneous inflammation signs (oral, hands or feet), (ii) hypotension or shock, (iii) features of myocardial dysfunction, pericarditis, valvulitis, or coronary abnormalities (including echocardiography [ECHO] findings or elevated troponin/ $\mathrm{N}$-terminal pro b-type natriuretic peptide [BNP]), (iv) evidence of coagulopathy (by Prothrombin time [PT], Partial thromboplastin time [PTT], and elevated d Dimer), and (v) acute gastrointestinal problems (diarrhea, vomiting, or pain abdomen), (3) elevated markers of inflammation such as erythrocyte sedimentation rate (ESR), C-reactive protein (CRP), or procalcitonin, (4) no other obvious microbial cause of inflammation, including bacterial sepsis, staphylococcal or streptococcal shock syndromes, (5) evidence of COVID-19 (Reverse transcription-polymerase chain reaction (RT-PCR), antigen test, or serology positive), or likely contact with patients with COVID-19. 40 cases which were admitted during the study period fulfilling the inclusion criteria were considered. Patients in whom an alternate diagnosis was obtained were excluded from the study (including bacterial sepsis, staphylococcal or streptococcal shock, Kawasaki disease, and tropical infections such as dengue, malaria, and rickettsial fever).

The study was approved by the Institutional Ethical Committee (ECR/134/Inst/KA/2013/RR-19, dated August 30, 2021). Clinical data of 40 children admitted during the study period in Cheluvamba Hospital, a tertiary care center, attached to Mysore Medical College and Research Institute, Mysuru, who fulfilled the diagnostic criteria established by the World Health Organization [4] were reviewed. Demographic details and history of COVID-19 infection or a contact with a confirmed case of COVID-19 were obtained. Virological data obtained either by nasopharyngeal secretions for RT-PCR/antigen test for (SARS-CoV-2) and/or serology for SARS-CoV-2 antibodies (immunoglobulin [Ig]M and/or IgG); and clinical data regarding the organ systems involved, treatment data, and immediate outcome were obtained.

Once the diagnostic criteria for MIS-C were fulfilled, all the cases underwent laboratory tests included under the tier 1 investigations: Complete blood count, renal function test, liver function test, serum electrolytes, blood culture and sensitivity, arterial blood gas analysis, CRP, and/or ESR. Tier 1 screening was said to be positive when both of the following were positive: (1) CRP $>5 \mathrm{mg} / \mathrm{L}$ and/or ESR $>40 \mathrm{~mm}$ per hour and (2) at least one of these: Absolute lymphocyte count
$<1000 / \mu \mathrm{L}$, platelet $<1.5 \mathrm{~L} /$ cumm, serum sodium: $<135 \mathrm{mmol} / \mathrm{L}$, neutrophilia, hypoalbuminemia, and Tier 2 investigations were obtained as per relevance. They were as follows: Cardiac: ECHO, electrocardiogram (ECG), BNP, troponin $\mathrm{T}$, Inflammatory markers: Procalcitonin, ferritin, PT, PTT, d Dimer, fibrinogen, lactate dehydrogenase (LDH), cytokine panel, blood smear, and SARS-CoV-2 serology.

The laboratory investigation reports were interpreted based on the age specific normal values. The demographic, clinical, and laboratory data obtained were compiled in a Microsoft excel sheet and analyzed. All the patients were treated according to the guidelines recommended by the Ministry of Health and Family Welfare, India, along with supportive care such as oxygen therapy, hydration therapy, inotropic support, and mechanical ventilation. All patients with MIS-C received methylprednisolone, under the coverage of broad-spectrum antibiotics, while, the children who presented with multiple organ dysfunction syndrome (MODS)/shock and Kawasaki phenotype, received Intravenous IG (IVIG) in addition.

\section{RESULTS}

In the study conducted in our tertiary health care center, 40 children (17 girls and 23 boys), who fulfilled the diagnostic criteria of MIS-C were included in the study. The mean age of the study population was 9.8 years. Only $12.5 \%$ of cases were having the history of COVID-19 infection, or a history of contact with a confirmed case of COVID-19 (7.5\%) in the past.

At admission, 67.5\% patients belonged to MODS/Shock phenotype, $2.5 \%$ patients had Kawasaki disease like presentation and the remaining $30 \%$ patients belonged to febrile inflammatory state (mild MIS-C).

The common presenting complaint in the study population is described in Table 1. In the tier 1 and tier 2 investigations for MIS-C, inflammatory markers were elevated in all the patients as shown in Table 2. The treatment strategies for the MIS-C patients are described in Table 3.

\section{Table 1: Clinical features of MIS-C}

\begin{tabular}{lcc}
\hline Symptoms & Number $(\mathbf{n}=\mathbf{4 0})$ & Percentage \\
\hline Fever & 40 & 100 \\
Vomiting & 29 & 72.5 \\
Pain abdomen & 18 & 45 \\
Hurried breathing/breathlessness & 17 & 42.5 \\
Diarrhea & 10 & 25 \\
Lethargy/Fatigue & 10 & 25 \\
Conjunctival congestion & 7 & 17.5 \\
Headache & 3 & 7.5 \\
Convulsions & 3 & 7.5 \\
Facial puffiness & 3 & 7.5 \\
Rash & 3 & 7.5 \\
Yellowish discoloration of skin/ & 3 & 7.5 \\
urine & & \\
Swelling of legs & 2 & 5 \\
\hline
\end{tabular}

MIS-C: Multisystem inflammatory syndrome in children 
Table 2: Laboratory data for MIS-C

\begin{tabular}{|c|c|c|c|c|}
\hline Conditions & Number & Percentage & Character & stics \\
\hline Anemia & 25 & 62.5 & Mean $\mathrm{Hb}$ & $11.11 \mathrm{~g} / \mathrm{dL}$ \\
\hline Leucopenia & 8 & 20 & $\begin{array}{l}\text { Mean } \\
\text { WBC } \\
\text { count }\end{array}$ & $\begin{array}{c}8.99 \times 10^{3} \\
\text { cells } / \mu \mathrm{L}\end{array}$ \\
\hline Lymphopenia & 9 & 22.5 & & \\
\hline Thrombocytopenia & 23 & 57.5 & $\begin{array}{l}\text { Mean } \\
\text { platelet } \\
\text { count }\end{array}$ & $\begin{array}{c}2.0 \\
\mathrm{~L} / \mathrm{cumm}\end{array}$ \\
\hline Neutrophilia & 11 & 27.5 & $\begin{array}{l}\text { Mean } \\
\text { ANC }\end{array}$ & $\begin{array}{l}5.8 \times 10^{3} \\
\text { cells } / \mu \mathrm{L}\end{array}$ \\
\hline Elevated Urea & 6 & 15 & & \\
\hline $\begin{array}{l}\text { Elevated } \\
\text { Creatinine }\end{array}$ & 2 & 5 & & \\
\hline Hyponatremia & 33 & 82.5 & $\begin{array}{l}\text { Mean } \\
\text { sodium }\end{array}$ & $\begin{array}{r}133.22 \\
\mathrm{mmol} / \mathrm{L}\end{array}$ \\
\hline Hypokalemia & 4 & 10 & $\begin{array}{l}\text { Mean } \\
\text { potassium }\end{array}$ & $\begin{array}{c}4.33 \\
\mathrm{mmol} / \mathrm{L}\end{array}$ \\
\hline $\begin{array}{l}\text { Elevated serum } \\
\text { total bilirubin }\end{array}$ & 7 & 17.5 & & \\
\hline $\begin{array}{l}\text { Elevated serum } \\
\text { direct bilirubin }\end{array}$ & 17 & 42.5 & & \\
\hline Elevated SGOT & 10 & 25 & & \\
\hline Elevated SGPT & 8 & 20 & & \\
\hline Hypoalbuminemia & 23 & 57.5 & & \\
\hline Elevated CRP & 32 & 80 & & \\
\hline Elevated ESR & 20 & 50 & & \\
\hline $\begin{array}{l}\text { Impaired PT/PTT/ } \\
\text { INR }\end{array}$ & 9 & 22.5 & & \\
\hline Elevated d-Dimer & 7 & 39 & Mean & 3015.52 \\
\hline $\begin{array}{l}\text { Elevated cardiac } \\
\text { troponin }\end{array}$ & 5 & 12.5 & & \\
\hline Elevated LDH & 38 & 95 & Mean & 885.21 \\
\hline $\begin{array}{l}\text { Elevated Serum } \\
\text { Ferritin }\end{array}$ & 36 & 90 & Mean & 1070 \\
\hline $\begin{array}{l}\text { Blood culture } \\
\text { showing growth }\end{array}$ & $\begin{array}{l}\text { MRSA } \\
\text { growth } \\
\text { (hospital } \\
\text { acquired) }\end{array}$ & 5 & & \\
\hline
\end{tabular}

Hb: Hemoglobin, WBC: White blood cells, ANC: Absolute neutrophil count, SGOT: Serum glutamic-oxaloacetic transaminase, SGPT: Serum glutamic-pyruvic transaminase, CRP: C-Reactive protein, ESR: Erythrocyte sedimentation rate, PT: Prothrombin time, PTT: Partial thromboplastin time, INR: International normalized ratio, LDH: Lactate dehydrogenase, MRSA: Methicillin-resistant Staphylococcus aureus, MIS-C: Multisystem inflammatory syndrome in children

Table 3: Treatment of MIS-C

\begin{tabular}{lcc}
\hline Treatment strategy & Number & Percentage \\
\hline Oxygen therapy & 22 & 55 \\
Mechanical ventilation & 8 & 20 \\
Inotropes/vasopressors & 16 & 40 \\
PICU requirement & 28 & 70 \\
Antiepileptic drugs & 3 & 7.5 \\
Methylprednisolone & 40 & 100 \\
IvIg & 20 & 50 \\
\hline
\end{tabular}

PICU: Pediatric Intensive Care Unit, IvIg: Intravenous immunoglobulin, MIS-C: Multisystem inflammatory syndrome in children

\section{DISCUSSION}

In mid-May, the team of pediatricians in Cheluvamba Hospital, noticed an unusual illness. The patients had prolonged fever and varied presentations involving all the organ systems and had elevated inflammatory markers. Significant number of them developed shock and organ dysfunctions. In such cases, bacterial causes were excluded and a majority of them had evidence of infection with SARS-CoV-2 in the past.

Our study was similar to an earlier study done by Whittaker et al., [5] where, the most common age group affected was between 11 and 15 years (50\%). In several published case series, some of the children have fever and mucocutaneous manifestations similar to those of Kawasaki disease, many other patients had presented with features of toxic shock syndrome and multiorgan dysfunction and others had mild febrile illness [6-9].

The most common presenting complaint in our study was similar as observed by Ahmed et al. [10] and Dhanalakshmi et al., [11]. The study done by Ahmed et al. [10] and Whittaker et al. [5] also had gastrointestinal system as the most common system involved while study done by Dhanalakshmi et al. [11] had mucocutaneous involvement as the most common symptom (74\%) in accord with our observation (Table 4).

Cardiovascular system was the most common system involved in the form of shock seen in 21 children (52.5\%). Among these 21 children, 2D ECHO was done in all; and seven (33.3\%) among them had abnormal findings. Two $(9.5 \%)$ had dilated coronary arteries, both had involvement of the left main coronary artery, five (23.8\%) revealed left ventricular hypertrophy and one patient (4.7\%) had mild pericardial effusion. An abnormal ECG was seen in six $(28.5 \%)$ children in the form of abnormal ST and T wave and prolonged PR interval. These results were similar to Dhanalaksmi et al. [11] and Jain et al. [12]. The laboratory findings correlate well with the study done by Ahmed et al. [10], Whittaker et al. [5], Dhanalakshmi et al. [11], and Jain et al. [12]. A comparison of our findings with other studies is summarized in Table 4.

All the patients were treated according to the guidelines recommended by the Ministry of Health and Family Welfare, India [13]. In all patients, tropical infections were ruled out and broad spectrum antibiotics were given. $70 \%$ of the patients required pediatric intensive care unit (PICU) care, with mean duration of PICU stay being 6.7 days.

In our study, the mortality rate was found to be $15 \%$, with all of them noticed to have multiorgan dysfunction during the course in the hospital and mortality was noticed highest among the children who initially presented with cardiovascular complaints.

However, the sample size of MIS-C patients is an important limitation of the current study. All the Tier 2 investigations including advanced cardiac markers could not be done in our setup. Some of the patients were lost to follow-up after discharge and hence long-term cardiac effects of MIS-C could not be studied in detail. Moreover, biologics such as Anakinra, Tocilizumab and infliximab were not used in cases of IVIG failure. 
Table 4: Comparison of findings with other studies

\begin{tabular}{|c|c|c|c|c|c|}
\hline Findings & $\begin{array}{l}\text { Our study at Cheluvamba } \\
\text { tertiary care center (mmcri) }\end{array}$ & $\begin{array}{l}\text { Ahmed } \\
\text { et al. }[10]\end{array}$ & $\begin{array}{l}\text { Whittaker } \\
\text { et al. [5] }\end{array}$ & $\begin{array}{l}\text { Dhanalakshmi } \\
\text { et al. }[11]\end{array}$ & $\begin{array}{c}\text { Jain } \\
\text { et al. }[12]\end{array}$ \\
\hline Median age & 9.8 years & 9.3 years & 9 years & 6 years & 7.2 years \\
\hline Fever $(\%)$ & 100 & 100 & 100 & 100 & \\
\hline Vomiting (\%) & 72.5 & 68.3 & 45 & 31.5 & \\
\hline Diarrhea $(\%)$ & 25 & 73.8 & 52 & 15.7 & \\
\hline Pain abdomen (\%) & 45 & & 53 & 42 & 52.1 \\
\hline Mucocutaneous (\%) & 20 & 56.2 & 52 & 74 & \\
\hline Conjunctival congestion (\%) & 17.5 & 51.8 & 45 & 47.3 & 52 \\
\hline CVS $(\%)$ & 40 & & & 63 & 65 \\
\hline Shock $(\%)$ & 52.5 & 60.1 & 50 & & 65 \\
\hline ECG changes $(\%)$ & 28.5 & 31.1 & & & \\
\hline 2D echo changes $(\%)$ & 33.3 & 87.8 & & & \\
\hline LV hypertrophy/dysfunction (\%) & 23.8 & 45.1 & & & 34.8 \\
\hline Coronary artery dilatation (\%) & 9.5 & 8.1 & 14 & 15.7 & 26 \\
\hline $\mathrm{CNS}(\%)$ & 17.5 & & & 31 & \\
\hline KD phenotype (\%) & 2.5 & & 22.4 & 36.8 & \\
\hline CRP $(\%)$ & 80 & 66.3 & & 100 & \\
\hline ESR $(\%)$ & 50 & 28.8 & & 81.8 & \\
\hline LDH $(\%)$ & 95 & 45.3 & & & \\
\hline Ferritin $(\%)$ & 90 & 45.7 & & 21.4 & \\
\hline Hyponatremia (\%) & 82.5 & & & 58 & \\
\hline Thrombocytopenia (\%) & 57.5 & & & 15.7 & \\
\hline Neutrophilia (\%) & 27.5 & 95 & & 68.4 & \\
\hline RT-PCR (\%) & 2.5 & & 26 & & 39.1 \\
\hline COVID antibody (IgM and IgG) (\%) & 97.5 & & 87 & & 30.4 \\
\hline PICU care and stay $(\%)$ & 70 & 71 & & 63 & \\
\hline $\operatorname{IvIg}(\%)$ & 50 & 76.4 & 83 & 79 & 65.2 \\
\hline Steroid $(\%)$ & 100 & 52.3 & 64 & 58 & 95.6 \\
\hline Mortality (\%) & 15 & 1.7 & 2 & 0 & 4.3 \\
\hline
\end{tabular}

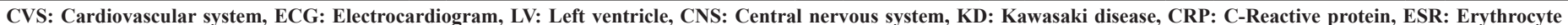

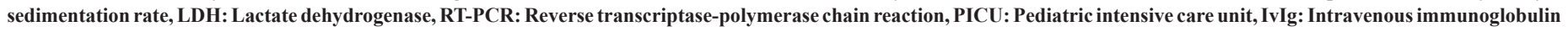

\section{CONCLUSION}

The corona virus disease had made catastrophic impact on health since the beginning of the pandemic. However, the disease was mild in most of the children, requiring comparatively lesser medical attention and intervention. However, MIS-C is a hyperinflammatory syndrome related to SARS-CoV-2 infection, where there is involvement of multiple organ systems. Early recognition and prompt medical attention are essential for a favorable outcome in MIS-C. However, there is scarcity of data regarding its long-term outcome. Hence, further multicentric, follow-up studies are required to clearly understand the pathogenesis, organ, or system wise predilection immediate as well as long-term manifestation and also the outcome of MIS-C.

\section{REFERENCES}

1. Godfred-Cato S, Bryant B, Leung J, Leung J, Oster ME, Conklin L, et al. COVID -19-assoicated multisystem inflammatory syndrome in
children-United States, March-July 2020. MMWR Morb Mortal Wkly Rep 2020;69:1074-80.

2. Rafferty MS, Burrows H, Joseph JP, Leveille J, Nihtianova S, Amirian ES. Multisystem inflammatory syndrome in children (MIS-C) and the Coronavirus pandemic: Current knowledge and implications for public health. J Infect Public Health 2021;14:484-94.

3. Dhar D, Dey T, Samim MM, Padmanabha H, Chatterjee A, Naznin P, et al. Systemic inflammatory syndrome in COVID-19-SISCoV study: Systematic review and meta-analysis. Pediatr Res 2021;18:1-16.

4. World Health Organization. COVID-19 Case Record Form for Suspected Cases of Multisystem Inflammatory Syndrome in Children and Adolescents Temporally Related to COVID-19 18 May 2020. Geneva: World Health Organization; 2020.

5. Whittaker E, Bamford A, Kenny J, Kaforou M, Jones CE, Shah P, et al. Clinical characteristics of 58 children with a pediatric inflammatory multisystem syndrome temporally associated with SARS-CoV-2. JAMA 2020;324:259-69.

6. Feldstein LR, Rose EB, Horwitz SM, Collins JP, Newhams MM, Son MB, et al. Multisystem inflammatory syndrome in U.S. children and adolescents. N Engl J Med 2020;383:334-46.

7. Matic KM. SARS-CoV-2 and multisystem inflammatory syndrome in children (MIS-C). Curr Probl Pediatr Adolesc Health Care 2021;51:101000.

8. Niño-Taravilla C, Otaola-Arca H, Lara-Aguilera N, Zuleta-Morales Y, Ortiz-Fritz P. Multisystem inflammatory syndrome in children, Chile, MayAugust 2020. Emerg Infect Dis 2021;27:1457-61. 
9. Choe YJ, Choi EH, Choi JW, Eun BW, Eun LY, Kim YJ, et al. Surveillance of COVID-19-associated multisystem inflammatory syndrome in children, South Korea. Emerg Infect Dis 2021;27:1196-200.

10. Ahmed M, Advani S, Moreira A, Zoretic S, Martinez J, Chorath K, et al. Multisystem inflammatory syndrome in children: A systematic review. EClinicalMedicine 2020;26:100527.

11. Dhanalakshmi K, Venkataraman A, Balasubramanian S, Madhusudan M, Amperayani S, Putilibai S, et al. Epidemiological and clinical profile of pediatric inflammatory multisystem syndrome-temporally associated with SARS-CoV-2 (PIMS-TS) in Indian children. Indian Pediatr 2020;57:1010-4.

12. Jain $\mathrm{S}$, Sen $\mathrm{S}$, Lakshmivenkateshiah $\mathrm{S}$, Bobhate P, Venkatesh S, Udani S, et al. Multisystem inflammatory syndrome in children with COVID-19 in Mumbai, India. Indian Pediatr 2020;57:1015-9.
13. Guidelines on Operationalization of COVID Care Services for Children and Adolescents. Government of India Ministry of Health and Family Welfare June, 2021; 2021. Available from: http://www.mohfw.gov.in. [Last accessed on 2021 Aug 30].

Funding: None; Conflicts of Interest: None Stated.

How to cite this article: Kottakki R, Rudrappa S, Patagar PM. Clinical and laboratory profile of multisystem inflammatory syndrome in children: A cross-sectional study in a tertiary care hospital, Mysuru. Indian J Child Health. 2021; 8(11):386-390. 